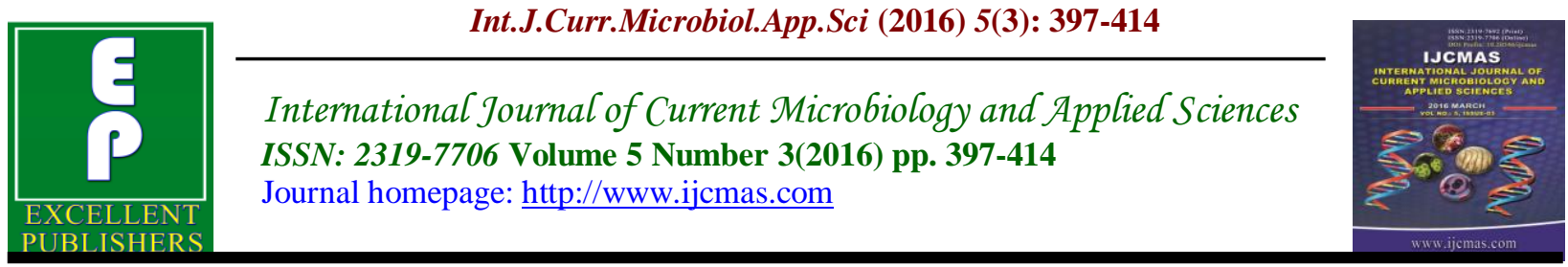

Original Research Article

http://dx.doi.org/10.20546/ijcmas.2016.503.047

\title{
A Comparative Study on Propolis and Pollen Extracts: Chemical Profile Analysis, Antioxidant and Anticancer Activity
}

\author{
Hala M. Abu Shady ${ }^{1}$, Wafaa F. mohamed ${ }^{2}$, ElSayed F. Sayed-Ahmed ${ }^{3}$ and Sara A. Amer ${ }^{3 *}$ \\ ${ }^{1}$ Faculty of Science, Ain Shams University, Egypt \\ ${ }^{2}$ Ain Shams University Specialized Hospital, Egypt \\ ${ }^{3}$ Food Technology Research Institute (FTRI), Agricultural Research Centre (ARC), Egypt \\ *Corresponding author
}

\begin{abstract}
A B S T R A C T
Keywords

Propolis and

Pollen Extracts,

Antioxidant and

Anticancer

Activity.

Article Info

Accepted:

18 February 2016

Available Online:

10 March 2016

Propolis and pollen are apicultural products exhibits valuable pharmacological and biological properties attributed to the presence of polyphenols. So this study designed to investigate the chemical composition, antioxidant and anticancer activity of propolis and pollen extracts. Propolis and pollen extracts were obtained by different concentrations of ethanol. Phenolic compounds of the extracts were detected by high performance liquid chromatography (HPLC) analysis. 25 phenolic compounds and 12 flavonoids from propolis and pollen extracts were identified. The major phenolic compounds were ethyl vanillin and hisperidin. $70 \%$ ethanolic extracts of propolis (EEP70) and combined mixtures of ethanolic propolis and pollen extracts (EPP70) has found to exhibit high antioxidant activity which has been measured by 1, 1-diphenyl-2-picryl-hydrazyl (DPPH) assay method. All tested extracts show cytotoxic activity against the two tested cancer cell lines: breast cancer (MCF-7) and liver cancer (Hep-G2) cell lines. Generally, 70\% ethanolic extract of propolis (EEP70), water extract of propolis (WEP) and combined mixtures of water extracted propolis and pollen (WPP) show the highest cytotoxic activity. This study may be useful in developing functional foods with high dietary antioxidant content or chemopreventive anticancer drugs with a potential to influence tumor cell progression.
\end{abstract}

\section{Introduction}

Antioxidant research has become a major scientific pursuit because of the evidence linking oxidative stress with many chronic diseases such as: the aging process, heart disease and cancer Gülçin et al. (2006). On the other hand, oxidation processes caused by reactive oxygen species are a major cause of deterioration of various food products, leading to significant undesirable changes in flavour, colour and texture and finally loss of nutritive value or complete spoilage Jaitak et al. (2010).

Antioxidants serve as a defensive factor against free radical's effects in the body. At the present, a variety of synthetic antioxidants are commonly used. However, the use of these compounds has been 
restricted by legislation due to doubts over their toxic and carcinogenic effects. Antioxidants with natural origin are considered to be multifunctional, and interesting alternatives to synthetic antioxidants, and which can be used to prevent diseases and the oxidation of complex food systems (Gülçin, 2010).

Honey bee-derived apicultural products such as propolis and pollen have been applied for centuries in traditional medicine as well as in food diets and supplementary nutrition due to their nutritional and physiological properties, above all in regard to their health effects on the human organism (Pereira et al., 2008; Basuny et al., 2013).

Propolis is a resinous material that is collected by honeybees from buds, leaves, bark, and exudates of several trees and plants (Lotti et al., 2010). Currently, more than 300 compounds, such as phenolic acid, terpenes, cinnamic acid, caffeic acid, several esters, and flavonoids have been identified as constituents of propolis from different geographic origins (Senedese et al., 2011; Huang et al., 2014). Propolis exerts numerous pharmacological benefits such as antioxidant, antibacterial, antiviral, antitumor, anti-inflammatory, anticancer and immunomodulatory activities (Basim et al., 2006; Kaewmuangmoon et al., 2012; Hongzhuan et al, 2014). While, pollen is a fine, powder-like material produced by flowering plants and gathered by bees. Pollen grains are the male reproductive cells of flowers (Basim et al., 2006). Pollen contains nutritional compounds like carbohydrates, proteins, amino acids, lipids, vitamins, minerals and traces of micronutrients (Campos et al., 2008). In addition, pollen contains significant amounts of polyphenolic substances, mainly flavonoids (Morais et al., 2011).
Pollen, as well as other apicultural products, has gained increased attention for its therapeutic properties, as antioxidant, antimicrobial, antitumor and immunomodulatory (Basim et al, 2006; Wang et al., 2013) effects. Other potential applications of pollen are its use in apitherapy and as a functional food in the food industry due to pollen nutritional properties. Bee gathered pollen is considered a valuable special food with varied enhancing effects in health (Bogdanov, 2004).

Several constituents of propolis and pollen are given the generally regarded as safe (GRAS) status (Burdock, 1998; Campos et al., 2008). Thus make propolis and pollen attractive candidates in developing a new natural preservative or for health perspective a new functional food.

The bioactive properties of apicultural propolis and pollen extracts can be increased using a solvent suitable for its extraction, improving the activity of free radicals sequestration (antirust activity) (Carpes et al., 2007; Sun et al., 2015). So our aims of this study were to investigate the bioactive compounds in pollen and propolis extracts which obtained by different ethanol/water solvent and evaluating the antioxidant and anticancer activity of these extracts.

\section{Materials and Methods}

\section{Preparation of Bee Products Extract}

Bee pollen and propolis samples (collected from the hybrid honey bee hives during the period of April to August in the year 2014) were purchased from Fayoum Governorate, Egypt and were stored at $4{ }^{\circ} \mathrm{C}$ until its processing. 
Extracts of bee products was prepared as the method described by Vongsak et al. (2015) and Carpes et al. (2007) with some modifications. each bee product sample (30g) were milled, homogenized and extracted individually using $300 \mathrm{~mL}$ of ethanol as extraction solvent in different concentrations $(98,70,0 \%)$ at temperature of $50^{\circ} \mathrm{C}$ for $30 \mathrm{~min}$ with constant agitation. Then each sample solution was stored in a dark place at $28^{\circ} \mathrm{C}$ for 1 day then stirred again with magnetic stirrer at $50^{\circ} \mathrm{C}$ for $30 \mathrm{~min}$. After that, solutions were filtered and concentrated under vacuum using the rotatory evaporator $\left(40^{\circ} \mathrm{C}\right)$. Then, solutions were evaporated under vacuum at $50^{\circ} \mathrm{C}$ until dryness to obtain the dried residue extract. Each residue was dissolved in its extracted solvent by $10 \%(\mathrm{w} / \mathrm{v})$ to obtain the following bee product stock extract:

\section{1-EEP 100 (propolis extracted in98\% ethanol)}

2-EEP 70 (propolis extracted in $70 \%$ ethanol)

3-WEP (propolis extracted in water)

4-EPE 100 (pollen extracted in 98\% ethanol

5-EPE 70 (pollen extracted in 70\% ethanol)

6-WPE (pollen extracted in water)

7-EPP 100 (EEP 100+EPE 100(1:1))

8-EPP 70 (EEP 70+EPE70(1:1))

9-WPP (WEP+WPE(1:1))

Chromatographic Determination of Phenolic and Flavonoid Compounds of Propolis and Pollen Extract

Phenolic and flavonoid compounds were determined using HPLC according to the method of Goupy et al. (1999) and Mattilla et al. (2000). Propolis and pollen dried residue extracts $(0.1 \mathrm{~g})$ were mixed with $10 \mathrm{~mL}$ methanol and filtered through a $0.2 \mu \mathrm{m}$ Millipore membrane filter then an amount of 1 to $3 \mathrm{~mL}$ was collected in a vial for injection into HPLC [Hewllet Packared (series 1050)] equipped with autosampling injector, solvent degasser, and quarter HP pump (series 1050). Ultraviolet (UV) detector was set at $280 \mathrm{~nm}$ and $330 \mathrm{~nm}$ for fenolic and flavonoid compounds, respectively. The column temperature was maintained at $35^{\circ} \mathrm{C}$. Gradient separation was carried out with methanol and acetonitrile as a mobile phase at flow rate of $1 \mathrm{~mL} / \mathrm{min}$. Standard used from Sigma co. were injected into HPLC. Retention time and beak area were used to calculate phenolic and flavonoid compounds concentrations by the data analysis of Hewllet Packared software.

\section{Antioxidant Activity of Propolis and Pollen Extracts}

The antioxidant activity of individual and combined extracts of propolis and pollen was determined on the basis of their scavenging activity of the stable 1, 1diphenyl-2-picryl hydrazyl (DPPH) free radical. DPPH is a stable free radical containing an odd electron in its structure and usually utilized for detection of the radical scavenging activity in chemical analysis.

The extracts and ascorbic acid as a positive control was separately dissolved in $(10 \%)$ dimethyl salfoxide (DMSO) at the concentration of $1 \mathrm{mg} / \mathrm{mL}$. for each extract, different concentrations ranging from $1 \mathrm{mg} / \mathrm{mL}$ to $0.0625 \mathrm{mg} / \mathrm{mL}$ were prepared with methanol. The reaction mixtures in the 96-well plates consisted of sample $(50 \mu \mathrm{l})$ and DPPH radical $(50 \mu 1,0.2 \mathrm{mM})$ dissolved 
in methanol. A control was prepared and contains $(50 \mu \mathrm{l})$ of DMSO instead of sample. The mixture was stirred and left to stand for $15 \mathrm{~min}$ in dark. Then the absorbance was measured at $517 \mathrm{~nm}$ with microplate reader against a blank. All determinations were performed in triplicates. The scavenging activity was calculated by the following equation:

Scavenging activity $(\%)=[$ (Absorbance of control - Absorbance of test sample) / Absorbance of control] $\times 100$

From the calibration curves, obtained from blotting different concentrations of extracts against corresponding scavenging activity, the $\mathrm{IC}_{50}$ was determined. $\mathrm{IC}_{50}$ value denotes the concentration of sample required to scavenge $50 \%$ of the DPPH free radicals (Wang et al., 2008)

\section{Cell Cytoxitity Assay}

\section{Cell Cultures}

Hepatocellular carcinoma (HepG2) and breast adenocarcinoma (MCF-7) human cancer cell lines were obtained from the America Type Culture Collection (ATCC, USA). MCF-7 cells were maintained in Eagle's minimum essential medium (EMEM) and HepG2 cells in Roswell Park Memorial Institute medium (RPMI-1640) medium. All the media contained Lglutamine, $10 \%$ fatal bovine serum (FBS), $1 \%$ penicillin and streptomycin and the cells were grown in T-75 flasks, with $5 \% \mathrm{CO}_{2}$ supply at $37^{\circ} \mathrm{C}$.

\section{Cell Viability Assay}

Cytotoxicity of individual and combined extracts of propolis and pollen was tested on two human cancer cell lines. Cell viability was determined as described by Houghton et al. (2007). Cells were seeded at the density of $4 \times 10^{4} / \mathrm{mL}$ into 96-well cell culture plates and were treated with different concentrations of extract $(25,50,100,200$, $400 \mu \mathrm{g} / \mathrm{mL}$ ). The final concentrations of DMSO in the medium did not exceed $1 \%$ and these concentrations of DMSO were not harmful to cell viabilities and morphologies. After $48 \mathrm{hr}$, cells were precipitated for $1 \mathrm{~h}$ at $4^{\circ} \mathrm{C}$ with $100 \mu 1 \quad 10 \%$ trichloroacetic acid and then plates were washed wit water and air dried. Plates were stained with SRB (sulphorhodamine) solution for $30 \mathrm{~min}$. The optical density was measured at $492 \mathrm{~nm}$ after reconstitution of the dye in $100 \mu \mathrm{l}$ $10 \mathrm{mM}$ Tris base. The optical density (OD) of SRB in each well is directly proportional to the cell number. The viability $(\%)$ was expressed as (OD of treated group/OD of control group) $\times 100$. The viability of the control cells was set to $100 \%$ and the $\mathrm{IC}_{50}$ determined by using Graph-Pad PRISM (GraphPad, UK).

\section{Results and Discussion}

In this study, a large variety of phenolic compounds were found in the propolis and pollen extracts and are presented in table 1,2. 25 phenolic acid and 12 flavonoids comounds from propolis and pollen extracts were identified. In propolis, the major phenolic compounds were ethyl vanillin, rosmarinic acid, salycilic acid, cinnamic acid, Pyrogallol and benzoic acid. While in pollen were ethyl vanillin, benzoic, Epicatechein and Caffeine, their percent are variable with different ethanol concentration but the lowest percent are mostly present in the water extract of either propolis or pollen. About flavonoids, hisperidin was abundantly detected in propolis extracts mainly in EEP $100 \quad(37.73 \mathrm{mg} / \mathrm{g})$ followed by hespertin(1.27 mg/g) and apegnin(1.26 $\mathrm{mg} / \mathrm{g}$ ); While in pollen, the highest flavonoid content was for hisperidin mainly 
in EPE100 $(7.7 \mathrm{mg} / \mathrm{g})$. Rutin was absent in all propolis extracts but it was present in detectable amount in pollen.

As shown in Fig. 1, 2, the percentage of DPPH free radical scavenging activity was increased in a concentration-dependent manner. The antioxidant activity of propolis and pollen extracts was comparable. However, The Highest effective extracts were EEP 70, EPP 70, EPE 70 followed by WEP with $\mathrm{IC}_{50}$ of $0.414,0.445,0.464$ and $0.471 \mathrm{mg} / \mathrm{mL}$. While the lowest antioxidant activity is observed with WPE with $\mathrm{IC}_{50}$ of $0.83 \mathrm{mg} / \mathrm{mL}$.

The anticancer activity of propolis, pollen extracts and their mixtures was assayed against two selected human cancer cell lines, MCF-7 and Hep-G2 cells, extracts exhibited anticancer activity against both selected human cancer cell lines.In liver cancer, the higher anticancer activity was observed with EEP70, WEP and WPP with $\mathrm{IC}_{50}$ of 62.5 , 70.31 and $70.9 \mathrm{ug} / \mathrm{mL}$, respectively (Table 3, Fig.3, 5). In breast cancer highist anticancer activity is observed with WEP followed by WPP then EEP100 and EEP 70 with $\mathrm{IC}_{50}$ of $70.3,100.2,124.2$ and 128.1ug/mL respectively (Table 4, Fig. 4,5).

In general anticancer activity of propolis is higher than pollen. Also, the anticancer activity observed against liver cancer cell line is greater than what observed against breast cancer cell line. The most surprising result is high activity of water extracted propolis (WEP) and the water extract of mixtures of propolis and pollen (WPP) against both cell lines.

In the recent years, there is a great attention towards exploring natural antioxidant that effectively scavenges free radicals or reactive oxygen species (ROS). Natural defense mechanisms eliminate negative effects of the activity of free radicals.
However, they are not always adequate to totally neutralize all endogenous and exogenous free radicals (Osuntoki and Korie, 2010). In this context, antioxidants, especially those derived from natural sources, demand special attention. So far, the recent focus of interest on plant phytochemicals, such as phenolic compounds which acting as primary antioxidants or free radical terminators (Rice-Evans et al., 1996). Propolis and pollen are one of the richest sources of plant phenolics (flavonoids and phenolic acids), which are widely recognized as rather strong antioxidants (Marcucci, 1995; Basuny et al., 2013)

The chemical composition of propolis is affected by climate conditions and the type of bee flora even when collected in the same country which results in variable biological activities (Hegazi and Abd El Hady, 2002; Chaillou and Nazareno, 2009). As well, pollen grains have specific characteristics according to the floral species or cultivation methods, but the quality depends on the collections process, cleanness, drying and storage applied by beekeepers with the objective to increase the products shelf-life. (Basuny et al., 2013). Accordingly, we have carried out chemical analysis to polyphenols compounds of propolis and pollen which have proved to be the key candidate for the biological activity (Banskota et al., 2001).

In this study, we used different concentrations of ethanol/water concentrations for extraction of propolis and pollen and the resultant phenolic compounds were analyzed by HPLC. Our results from HPLC analysis indicates the presence of different phenolic compounds and flavonoids among them hisperidin and ehylvanillin were found in high amounts. Hesperidin is one such naturally occurring flavonoid widely found in citrus fruits, belongs to the class of flavonoids called 
flavanones, subsequently, the floral source of these bee products may belong mostly to citrus fruits. The reported major flavonoids that were isolated from Egyptian propolis were quercentin, pinostrobin, chrysin and galangin (Haggag et al., 2006). In our previous work, we found that the highest amounts account for naringenin and vanillic acid (Abu Shady et al., 2011) in WEP obtained by Najafi et al. (2007) extraction method. In this study, Rutin cannot be quantified; probably due to the interference with other similar compounds (like saccharide derivatives) (Coneac et al., 2008) In addition, Slavova et al. (2013) reported presence of rutin in half only of analyzed samples with better results for commercial products than for propolis extracts obtained in the laboratory.

Several parameters may influence the yield and type of phenolics, including extraction time, temperature, solvent-to-sample ratio, the number of repeat extractions of the sample, as well as solvent type. Furthermore, the optimum recovery of phenolics is different from one sample to the other and relies on the type of plant and its active compounds (Garcia-Salas et al., 2010). Pollen and propolis were found to be rich in phenolic compounds and flavonoids. In addition, these extracts contained a wide variety of phenolics ranged from polar compounds to weak-polar and also apolar compounds. That results were in harmony with those observed with other researchers who reports that ethanol or ethanol/water solvent is suitable for extracting some bioactive compounds with broad range of polarity (Sun et al., 2015).

Antioxidant capacity is widely used as a parameter for medicinal bioactive components. In the present study, we have investigated antioxidant activity of the extracts by using DPPH assay method. The results of the DPPH assay emphasize a dosedependent antioxidant activity of the extracts, and the highest antioxidant activity was obtained with concentration $70 \%$ ethanol extract of either propolis, pollen or their mixtures followed by the water extract of propolis. The antioxidant activity of vitamin $\mathrm{c}$ was obviously higher than propolis and pollen extracts, which resembles the results obtained by Hegazi and Abd El Hady (2002). IC 50 for all extracts was ranged 0.414 to $0.83 \mathrm{mg} / \mathrm{mL}$ for EEP70 and WPE respectively. The $\mathrm{IC}_{50}$ for propolis extracts was ranged from 0.698 to $0.414 \mathrm{mg} / \mathrm{mL}$ and the lowest $\mathrm{IC}_{50}$ recorded by EEP70. The obtained percent is within the range obtained with Mărghitas et al (2009) as they found that $\mathrm{IC}_{50}$ for all Transylvanian propolis samples ranged from 0.3 to $5.6 \mathrm{mg} / \mathrm{mL}$. Also our results were in harmony with Sun et al (2015) as they found that the $\mathrm{IC}_{50}$ values of different propolis extracts varied from $13798 \mu \mathrm{g} / \mathrm{ml}$ to 633 $\mu \mathrm{g} / \mathrm{ml}$ and they added that $75 \%$ EEP especially exhibited the strongest DPPH radical-scavenging activity; its $\mathrm{IC}_{50}$ value was $633 \mu \mathrm{g} / \mathrm{mL}$, much lower than that of WEP. Meanwhile, in pollen extracts we found that $\mathrm{IC}_{50}$ ranged from 0.464 to $0.83 \mathrm{mg} / \mathrm{mL}$. And these results were superior to those found by Meda et al (2005), who analysed 27 samples from Burkina Faso. These authors found a mean $\mathrm{IC}_{50}$ value of $10.60(\mathrm{mg} / \mathrm{mL})$. Also to Morais et al (2011) who studied Portuguese bee pollen from Natural Parks and found $\mathrm{IC}_{50}$ ranged from 5.87 to $2.16 \mathrm{mg} / \mathrm{mL}$. However, our results have similarity with the data obtained by Basuny et al (2013) who found that $\mathrm{IC}_{50}$ for palm pollen extract was $0.62 \mathrm{mg} / \mathrm{mL}$ also with Carpes et al (2009) who found that $\mathrm{IC}_{50}$ for pollen ranged from 0.8 to $4.69 \mathrm{mg} / \mathrm{mL}$ for pollen collected from Southern Brazil. Also, highest degree of antioxidant activity was found in the extraction at $60 \%$ of ethanol solution for Parana state pollen, 
which also showed the highest concentration of polyphenol compounds (Carpes et al., 2007). About the mixtures of propolis and pollen extracts, the $\mathrm{IC}_{50}$ is generally moderate between pollen and propolis and this suggested that these mixtures can be used also as a potent antioxidant, which gathered the functional and pharmacological activities of both extracts.

Several studies have correlated polyphenolic composition of propolis with its antioxidant properties (Kumazawa et al., 2004; Gregoris and Stevanato, 2010). In addition, the redox properties of polyphenol compounds, especially flavonoids, play an important role in absorbing and neutralising free radicals, quenching oxygen and decomposing peroxides. It is known that only flavonoids of a certain structure and particularly hydroxyl position in the molecule, determine antioxidant properties. In general, these properties depend on the ability to donate hydrogen or electron to a free radical (Mărghitaş et al., 2009).

Propolis and pollen extracts in our results have a large variety of phenolic component which are rather known for their antioxidant so it is difficult to correlate their activity with one component and their activity is due to the synergy between the blends of phenolic component rather than one component, this results is familiar with those obtained by (sun et al., 2015).

Hajimehdipoor et al. (2014) have tested synergistic antioxidant effects of some phenolic and flavonoids, compounds and found that some combinations have considerable synergistic effects like combination of gallic acid and caffeic acid $(137.8 \%)$ while other combinations were less potent. Among examined substances, rutin was the only one which had no effect on the other compounds.
The antioxidant capacity of a compound can assist in the prevention of diseases related to oxidative stress, which is caused by an imbalance between the formation and neutralization of free radicals in the body through enzymatic and non-enzymatic antioxidants (Fang et al., 2002). Among these stress related diseases is cancer. Cancer is one of the main causes of mortality in the world which is created by the effect of enviromental physico-chemical mutagen and carcinogen agents (Dehghani et al., 2015). It accounting for 7.6 million deaths in 2008 or $13 \%$ of all deaths recorded (World Health Organization, 2013).

Despite the availability of several anticancer agents, the treatment of cancer remains medical hurdle in the developed and developing countries. Discovery of natural products with potential anticancer activity is very initiative trend in countries with rich botanical flora (Mahmoud and Shemy, 2012).

Based upon results of National Cancer Registry Program (NCRP), cancer incidence rates at national and regional level of Egypt indicated that liver cancer occupied first rank and breast cancer occupied a second rank (Ibrahim et al., 2014). Herein, we have assessed the cytotoxic characteristic of propolis, pollen and their mixtures against HepG2 liver cancer cell line and MCF-7 breast cancer cell line. Liver cancer is very serious solid tumor which is highly abundant in areas endemic with hepatitis viruses such as middle and Far East (Mahmoud and Shemy, 2012). The present results show a potent anticancer activity of all extracts especially with ethanolic $(70 \%)$ and water extract of propolis. Proliferation of MCF7 cells and HepG2 were remarkably inhibited by propolis and pollen extracts in a dosedependent manner. $\mathrm{IC}_{50}$ value for $\mathrm{HepG} 2$ was ranged from 62.65 to $272.1 \mu \mathrm{g} / \mathrm{mL}$ for 
EEP70 and EPP70, respectively. While, $\mathrm{IC}_{50}$ value for $\mathrm{MCF} 7$ was ranged from 70.3 to $246.15 \mu \mathrm{g} / \mathrm{mL}$ for WEP and EPE 70. The cytotoxic activity of propolis extracts is generally higher than pollen extracts.

Table.1 Hplc Analysis for Phenolic Compounds of Propolis and Pollen Dried Extract (Mg/G)

\begin{tabular}{|lcccccc||}
\hline Phenolic compounds & EEP 100 & EEP 70 & WEP & EPE 100 & EPE 70 & WPE \\
\cline { 2 - 7 } & & & & & & \\
Gallic & 0.24843 & 0.26243 & 0.23341 & 0.04657 & 0.17301 & 0.03850 \\
Pyrogallol & 0.94038 & 0.51587 & 0.76416 & 0.12418 & 0.63550 & 0.52791 \\
4-Amino-benzoic & 0.05731 & 0.02332 & 0.05888 & 0.01008 & 0.04916 & 0.03996 \\
3-Hydroxy tyrosol & 0.15208 & 0.09016 & 0.11824 & 0.04445 & 0.11701 & 0.06199 \\
Protocatchuic & 0.3445 & 0.1408 & 0.2537 & 0.0878 & 0.5257 & 0.2571 \\
Chlorogenic & 0.33204 & 0.22288 & 0.33115 & 0.16699 & 0.19352 & 0.1535 \\
Epicatechein & $\mathrm{ND}$ & 0.22775 & $\mathrm{ND}$ & 0.29634 & 0.77269 & 0.25045 \\
Catechein & 0.3355 & 0.10811 & 0.07505 & 0.07891 & 0.13721 & 0.06382 \\
Catechol & 0.27266 & 0.15486 & 0.28159 & 0.12519 & 0.21179 & 0.07299 \\
Caffeine & 0.10533 & $\mathrm{ND}$ & 0.15959 & 1.52533 & 1.80505 & ND \\
P-OH-benzoic & 0.21418 & 0.26193 & 0.19577 & 0.15745 & 0.24274 & 0.3049 \\
Caffeic & 0.07631 & 0.07672 & $\mathrm{ND}$ & $\mathrm{ND}$ & 0.12454 & 0.08601 \\
Vanillic & 0.09313 & 0.05034 & 0.06482 & 0.04742 & 0.11487 & 0.01606 \\
P-Coumaric & 0.11700 & 0.06057 & 0.05447 & 0.26335 & 0.21813 & 0.08394 \\
Ferulic & 0.02742 & 0.02055 & 0.03136 & 0.07147 & 0.05299 & 0.00985 \\
Iso-Ferulic & 0.60867 & 0.34578 & 0.26174 & 0.10351 & 0.14692 & 0.02153 \\
Resveratrol & 0.01480 & 0.0655 & 0.03412 & 0.02145 & 0.11256 & 0.02048 \\
Ellagic & 0.03158 & 0.25579 & 0.21116 & 0.39161 & 0.5556 & 0.03764 \\
E- vanillic & 9.34044 & 1.11227 & 2.19772 & 32.2338 & 6.90978 & 3.19740 \\
Alpha-Coumaric & 0.26941 & 0.1402 & 0.09681 & 0.15733 & 1.05835 & 0.04205 \\
Rosmarinic & 3.11329 & 0.92025 & 1.46545 & 0.86531 & 1.67075 & 0.26707 \\
Benzoic & 0.73028 & 0.42668 & 0.39667 & 0.42128 & 3.61731 & 0.05039 \\
3,4,5-methoxy-cinnamic & 0.21733 & 0.04172 & 0.04533 & 0.43409 & ND & 0.0322 \\
Coumarin & 0.23416 & 0.1903 & 0.15052 & 0.16476 & 0.34544 & 0.01966 \\
Salycilic & 1.6227 & 1.6537 & 0.29964 & 0.3476 & 2.17662 & 0.160417 \\
Cinnamic & 1.8094 & 0.86724 & 0.61811 & 0.02619 & 0.03150 & 0.00839 \\
\hline
\end{tabular}

EEP100: propolis extracts extracted with 98\% ethanol, EEP 70: propolis extracted with 70\% ethanol, WEP extracted with 100\% water, EPE 100: pollen extracts extracted with 98\% ethanol, EPE 70: pollen extracted with 70\% ethanol, WPE extracted with $100 \%$ water 
Table.2 HPLC Analysis for Flavonoid Compounds of Propolis and Pollen Dried Extract (Mg/G)

\begin{tabular}{|ccccccc|}
\hline $\begin{array}{c}\text { Flavonoid } \\
\text { compounds }\end{array}$ & EEP 100 & EEP 70 & WEP & EPE 100 & EPE 70 & WPE \\
\cline { 2 - 7 } Luteolin & 0.16246 & 0.15585 & 0.09616 & 0.14251 & 0.32780 & 0.07055 \\
Naringin & 0.10971 & 0.09056 & 0.08567 & 0.15771 & 0.09599 & 0.04751 \\
Rutin & ND & ND & ND & 0.06204 & 0.143357 & 0.027494 \\
Hisperidin & 37.7363 & 22.150 & 19.1891 & 7.74522 & 1.84851 & 0.21010 \\
Quercetrin & 0.43289 & 0.17885 & 0.07146 & 2.83276 & 6.97191 & 0.26220 \\
Quercetin & 0.18833 & 0.26684 & 0.05137 & 0.14829 & 0.87329 & 0.04365 \\
Kaempferol & 0.28982 & 0.56336 & 0.16104 & 0.09487 & 0.22224 & 0.02442 \\
Hespertin & 1.27408 & 0.85390 & 0.33323 & 0.27379 & 0.36898 & 0.14858 \\
Apegnin & 1.2635 & 0.55401 & 0.025248 & 0.034167 & 0.041689 & 0.00665 \\
7- Hyd- Flavone & 0.11209 & 0.01485 & 0.01323 & 0.003062 & 0.003167 & 0.000272 \\
Luteolin & 0.16246 & 0.15584 & 0.09616 & 0.14251 & 0.32780 & 0.07055 \\
\hline
\end{tabular}

EEP100: propolis extracts extracted with 98\% ethanol, EEP 70: propolis extracted with 70\% ethanol, WEP extracted with 100\% water, EPE 100: pollen extracts extracted with 98\% ethanol, EPE 70: pollen extracted with 70\% ethanol, WPE extracted with 100\% water

Table.3 Effect of Propolis and Pollen Extracts and their Mixtures n the Cytotoxicity Parameter of Hepg-2 (Liver Cancer) Cell Line

\begin{tabular}{|ccccccc|}
\hline \multirow{2}{*}{ Parameter } & \multicolumn{5}{c|}{ Concentrations of extracts $(\boldsymbol{\mu g} / \mathbf{m l})$} \\
\cline { 2 - 6 } Extracts & $\mathbf{2 5}$ & $\mathbf{5 0}$ & $\mathbf{1 0 0}$ & $\mathbf{2 0 0}$ & $\mathbf{4 0 0}$ & $\mathbf{I C}_{\mathbf{5 0}}$ \\
\cline { 2 - 7 } & & & & & \\
EEP100 & 86.59 & 74.58 & 58.78 & 29.66 & 5.52 & 122.1 \\
EEP70 & 86.14 & 57.70 & 38.52 & 22.99 & 6.48 & 62.65 \\
WEP & 79.34 & 67.77 & 35.92 & 19.60 & 9.61 & 70.31 \\
EPE100 & 92.74 & 70.34 & 64.87 & 49.39 & 20.70 & 194.1 \\
EPE70 & 98.99 & 81.91 & 77.71 & 16.72 & 15.74 & 131.2 \\
WPE & 93.81 & 88.89 & 70.81 & 25.24 & 23.99 & 134.5 \\
EPP100 & 82.23 & 75.56 & 58.27 & 33.79 & 13.81 & 127.5 \\
EPP70 & 91.31 & 78.36 & 75.94 & 69.40 & 14.04 & 272.1 \\
WPP & 77.51 & 63.32 & 37.18 & 24.21 & 6.02 & 70.978 \\
\hline
\end{tabular}

EEP100: propolis extracts extracted with 98\% ethanol, EEP 70: propolis extracted with 70\% ethanol, WEP extracted with 100\% water, EPE 100: pollen extracts extracted with $98 \%$ ethanol, EPE 70: pollen extracted with 70\% ethanol, WPE extracted with 100\% water.EPP100: EEP100+EPE 100(1:1), EPP70: EEP 70+EPE 70(1:1),WPP: WEP+WPE(1:1) 
Table.4 Effect of Propolis and Pollen Extracts and their Mixtures on the Cytotoxicity Parameters of Mcf-7 Breast Cancer Cell Line

\begin{tabular}{|c|c|c|c|c|c|c|}
\hline \multirow{3}{*}{$\begin{array}{l}\text { Parameter } \\
\text { Extracts }\end{array}$} & \multicolumn{6}{|c|}{ Concentrations $(\mu \mathrm{g} / \mathrm{ml})$} \\
\hline & 25 & 50 & 100 & 200 & 400 & $\mathrm{IC}_{\mathbf{5 0}}$ \\
\hline & \multicolumn{6}{|c|}{ Cytotoxicity $(\%)$} \\
\hline EEP100 & 90.91 & 76.54 & 55.22 & 41.83 & 24.64 & 128.1 \\
\hline EEP70 & 87.97 & 79.99 & 56.17 & 38.57 & 23.08 & 124.2 \\
\hline WEP & 58.51 & 54.94 & 44.73 & 32.2 & 14.85 & 70.3 \\
\hline EPE100 & 73.33 & 70.67 & 56.48 & 52.62 & 28.46 & 224.1 \\
\hline EPE70 & 96.19 & 75.35 & 65.08 & 57.70 & 20.75 & 246.15 \\
\hline WPE & 76.75 & 69.67 & 56.37 & 49.31 & 6.53 & 192.08 \\
\hline EPP100 & 84.74 & 78.82 & 62.39 & 45.01 & 15.76 & 170.27 \\
\hline EPP70 & 72.29 & 60.59 & 56.45 & 37.34 & 23.98 & 131.2 \\
\hline WPP & 76.46 & 63.01 & 50.58 & 35.48 & 21.32 & 102.06 \\
\hline
\end{tabular}

EEP100: propolis extracts extracted with 98\% ethanol, EEP 70: propolis extracted with 70\% ethanol, WEP extracted with 100\% water, EPE 100: pollen extracts extracted with 98\% ethanol, EPE 70: pollen extracted with 70\% ethanol, WPE extracted with 100\% water.EPP100: EEP100+EPE 100(1:1), EPP70: EEP70+EPE70(1:1), WPP: WEP+WPE(1:1)

Fig.1 Scavenging Activity (\%) of Propolis, Pollen Extracts and their Combined Mixtures
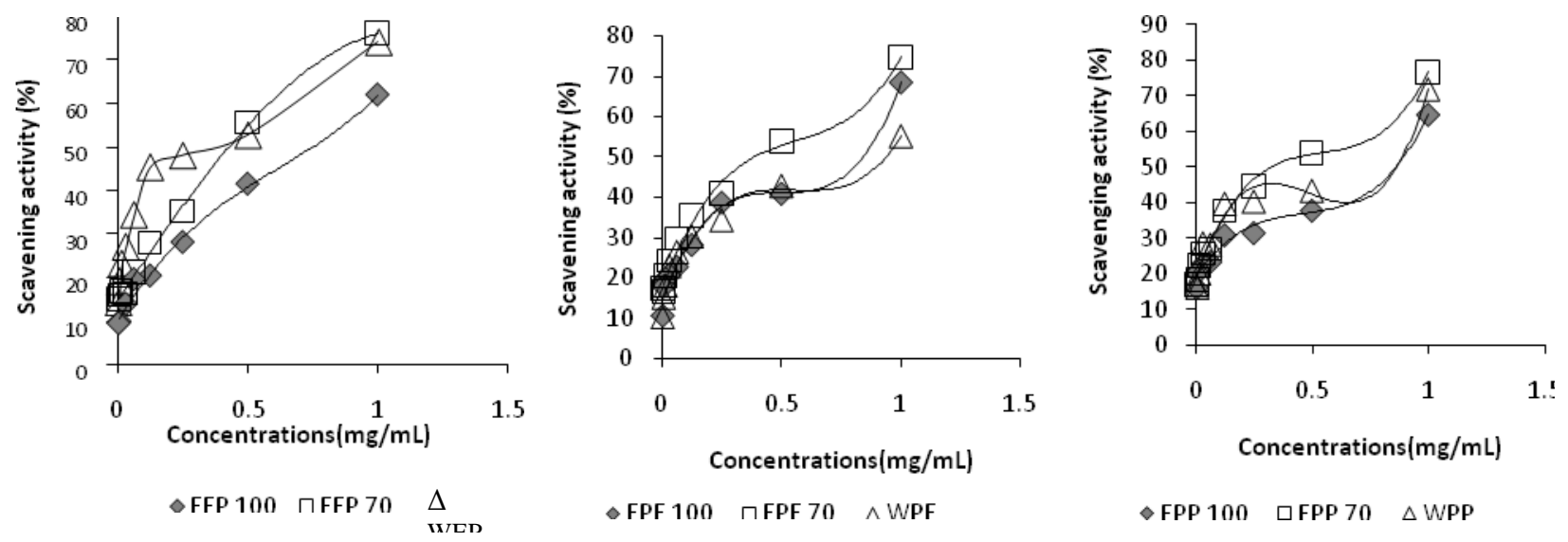

EEP100: propolis extracts extracted with 98\% ethanol, EEP 70: propolis extracted with 70\% ethanol, WEP extracted with 100\% water, EPE 100: pollen extracts extracted with 98\% ethanol, EPE 70: pollen extracted with 70\% ethanol, WPE extracted with 100\% water. EPP100: EEP100+EPE 100(1:1), EPP70: EEP 70+EPE 70(1:1),WPP: WEP+WPE(1:1) 
Fig.2 Scavenging Activity of Propolis and Pollen Extracts and their Mixtures, Expressed as IC50

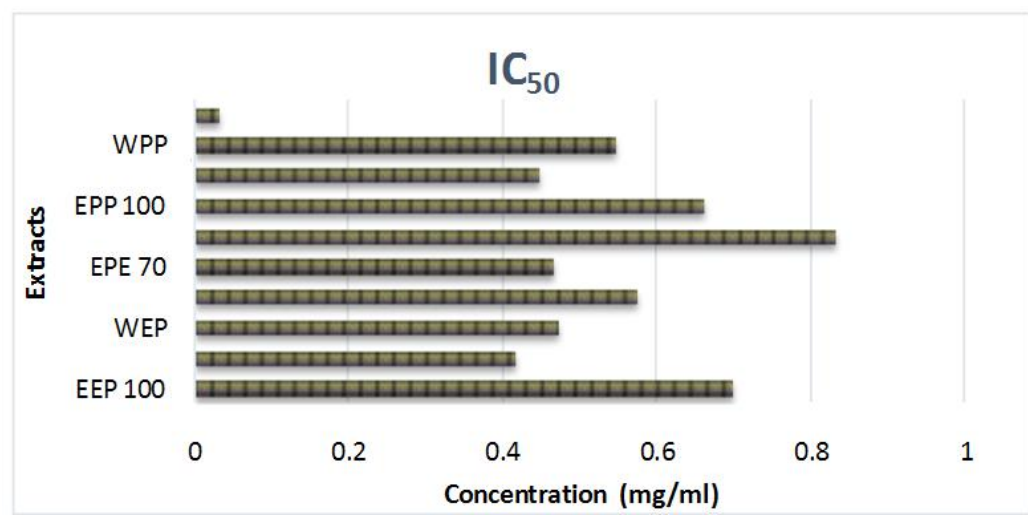

EEP100: propolis extracts extracted with 98\% ethanol, EEP 70: propolis extracted with 70\% ethanol, WEP extracted with $100 \%$ water, EPE 100: pollen extracts extracted with 98\% ethanol, EPE 70: pollen extracted with 70\% ethanol, WPE extracted with 100\% water.EPP100: EEP100+EPE 100(1:1), EPP70: EEP 70+EPE 70(1:1),WPP: WEP+WPE(1:1)

Fig.3 Effect of Propolis and Pollen Extracts and their Mixtures on the Cytotoxicity Parameters of Hepg-2 (Liver Cancer) Cell Line
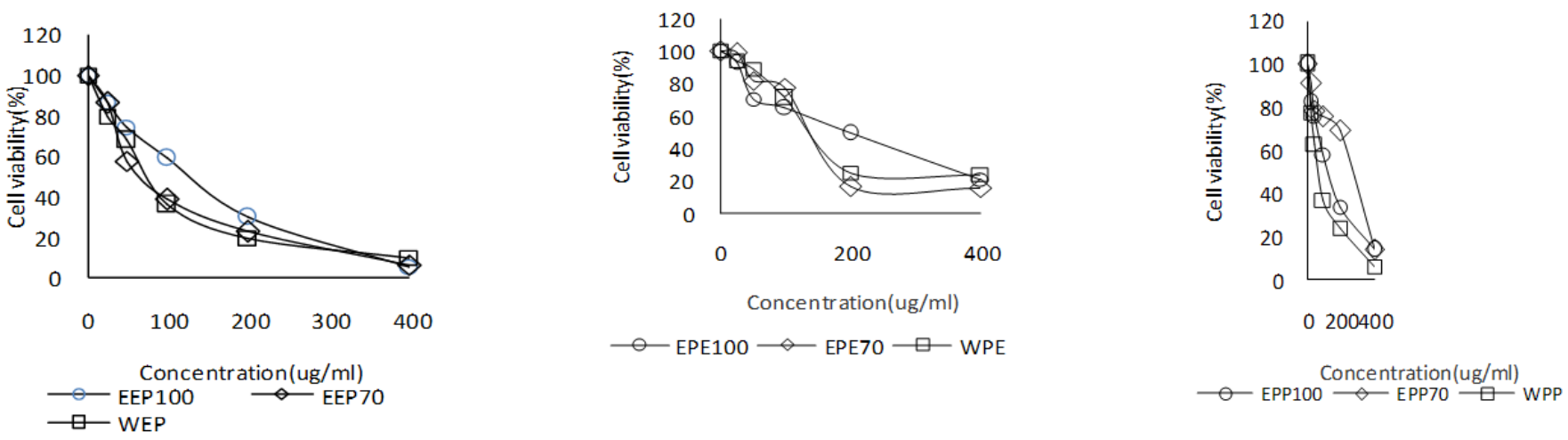

Fig.4 Effect of Propolis and Pollen Extracts and their Combined Mixtures on the Cytotoxicity Parameters of Mcf-7 Breast Cancer Cell Line
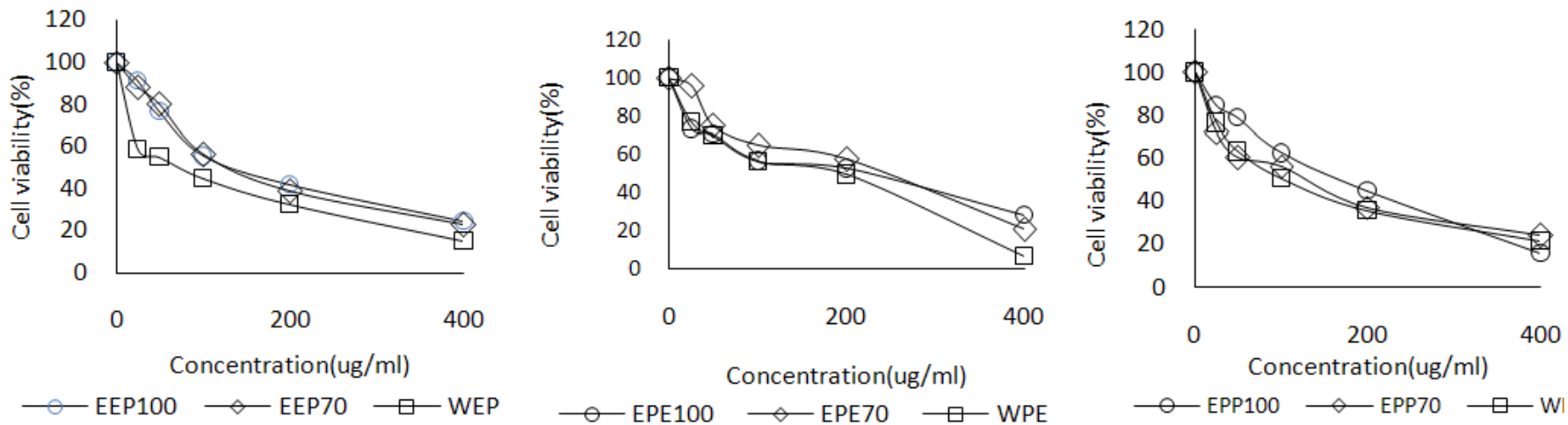
Fig.5 Comparison of Ic50 of Propolis, Pollen Extracts and their Combined Mixtures Recorded Against Hepg-2 And Mcf-7 Cell Line

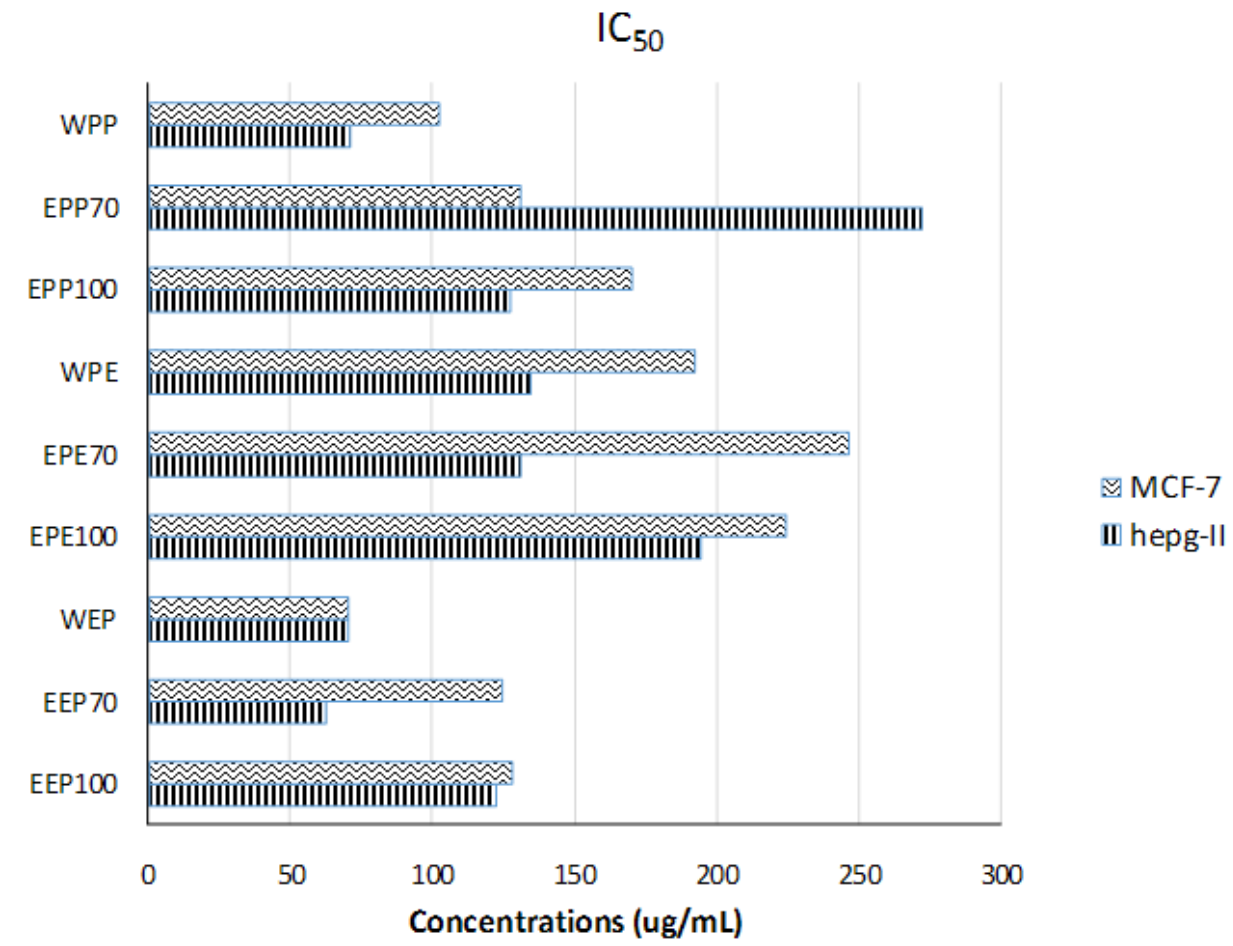

Many reports have indicated that different types of propolis extracts significantly inhibit cell growth and reduce the differentiation or proliferation of tumor cells (Zliszka et al., 2011; Khalil, 2006).Vatansever et al. (2010) reported cytotoxicity of EEP at a concentration of $125 \mu \mathrm{g} / \mathrm{mL}$ to MCF-7 cell line also they found that cytotoxic effects of seven EEP samples collected from the same location is different. While, Choudhari et al. (2013) found that $\mathrm{IC}_{50}$ for ethanolic extract of propolis (EEP) of four cancer cell lines: human colon adenocarcinoma (HT-29), human epithelial colorectal adenocarcinoma (Caco-2), and murine melanoma cell lines (B16F1), MCF-7 to be $250 \mu \mathrm{g} / \mathrm{mL}$. In another study, Campos et al. (2014) reported that EEP promoted cytotoxic activity and primarily necrotic death in K562 erythroleukemia cells (Barzin et al., 2011; Campos et al., 2014). On the other hand, fewer studies reported cytotoxicity of bee pollen (Barzin et al., 2011). A study reports that polysaccharides from pollen of Rosa rugosa can inhibit the proliferation of HT-29 and HCT116 colon cancer cell lines in a dose-dependent manner in vitro, indicating a potential antitumor activity (Wang et al., 2013). When looking in phenolic compounds one can predict such cytotoxic activity. For example, hesperidin has several biological functions such as antioxidant, anti-inflammatory, anti-mutagenic activity (Sobolova et al., 2006; Al-Jasabi and Abdullah, 2013) Hesperidin induced cytotoxicity in MCF-7 cells in vitro. Apoptosis of MCF-7 cells may be due to the DNA damage and expression of apoptotic proteins (Natarajan et al., 2011). Ethyl vanillin and vanillin exerted stronger antioxidant effects than did vanillyl alcohol or vanillic acid (Tai et al., 2011). Rosmarinic acid has antioxidant, anti- 
inflammatory and antimicrobial activities. Rosmarinic acid helps to prevent cell damage caused by free radicals, thereby reducing the risk for cancer and atherosclerosis (Hossan et al., 2014). Luteolin has found to inhibit proliferation of MCF-7 (breast cancer) and HepG2 (liver cancer) cells in a dose-dependent manner (Wang et al., 2007; Seelinger et al., 2008). Quercetin has been proven to be a potent component in antioxidant and anticancer against human cancer cell lines, MCF-7, Hep-G2 and NCI-H460 (Son and Anh, 2013).

The main compounds responsible for the anti-tumor activity of propolis include flavonoids, terpenes and caffeic acid phenethyl ester, and this activity could be attributed to synergism between the substances present in the resin (Valente $e t$ al., 2011; Watanabe et al., 2011). Its possible mechanisms of action against tumours, involving apoptosis, cell cycle arrest and interference on metabolic pathways (Watanabe et al., 2011). Also polyphenols of pollen have been reported to be responsible for their antioxidant activity (Ohta et al., 2007). Subsequently, reducing the risk of free radicals, genotoxic substance or carcinogenics (Tang et al., 2005). Morover, in our study there were interesting finding of WEP which recorded $\mathrm{IC}_{50}$ of 70.3 $\mu \mathrm{g} / \mathrm{mL}$ on both tested cell lines.

Furthermore, WPP shows considerable anticancer activity with $\mathrm{IC}_{50}$ of 70.9 and $102.06 \mu \mathrm{g} / \mathrm{mL}$ on liver and breast cancer lines, respectively. Although, the most common propolis extracting process uses ethanol as a solvent, However, WEP is preferred; because of EEP has some disadvantages such as the strong residual flavor, adverse reactions, intolerance to alcohol of some people and some solubility problems (Konishi et al., 2004).
Mixtures of propolis and pollen show almost moderate $\mathrm{IC}_{50}$, except in case of EPP70 which its recorded $\mathrm{IC}_{50}$ higher than individual component. To the best of our knowledge, this is the first study investigating the anticancer activity of propolis and pollen mixtures and that give possibility of take benefits of both extracts at lower doses. It is worth to mention that early studies have found propolis to be relatively non-toxic to humans or mammals unless very large quantities are administered (Kaneeda and Nishina, 1994; Mohammadzadeh et al., 2007) In addition, a safe dose of $1.4 \mathrm{mg} / \mathrm{kg}$ body weight/day has been proposed by Burdock (1998).

In conclusion, Egyptian propolis and pollen were found to be rich in polyphenol and which were solvent dependant. Additionally, the tested epiculture products or their mixtures have been proven to be a potent component in antioxidant and anticancer activity against the two selected human cancer cell lines: liver and breast cancer cell line. Different behavior of the combined extracts can be attributed to the chemical properties, nature and reactivity of the components of the extracts. The obtained results indicate that this natural bee product exhibits promise for the treatment and/or prevention of various diseases related to oxidative stress and tumor cell proliferation and from health prospective, production of a new functional food.

\section{References}

Abu Shady, H.M., W.F., Mohamed, G.H., Ghonemy, Amer, S.A. 2011. Individual and combined antioxidant activity of Egyptian propolis and lactic acid bacteria. Egypt. J.Bot., 51(2): 201-215.

Al-Jasabi, S., Abdullah, M.S. 2013. The Role of Antioxidant Hesperidin in 
the Attenuation of Lung Cancer Caused by Benzo[a]pyrene in Balb/c Mice. World Appl. Sci. J., 22(8): 1106-1110.

Banskota, A.H., Tezuka, Y., Kadota, S.H. 2001. Recent progress in pharmacological research of propolis. Phytother. Res., 15: 561571.

Barzin, G.M., Entezari, M., Hashemi, S., Hajiali, M., Ghafoori, Gholami, M. 2011. Survey of Antimutagenicity and Anticancer effect of Phoenix dactylifera pollen grains. $A d v$. Environ. Biol., 5(12): 3716-3718.

Basim, E., Basim, H., Ozcan, M. 2006. Antibacterial activities of Turkish pollen and propolis extracts against plant bacterial pathogens. J. Food Engineering, 77: 992-996.

Basuny, A.M., Arafat, S.M., Soliman, H.M. 2013. Chemical analysis of olive and palm pollen: Antioxidant and antimicrobial activation properties. Herald J. Agric. Food Sci. Res., 2(3): $091-097$.

Bogdanov, S. 2004. Quality and standards of pollen and beeswax. Apiacta, [S.1.]. 38: 334-341.

Burdock, G.A. 1998. Review of the Biological Properties and Toxicity of Bee Propolis. Food Chem. Toxicol., 36: 347-363.

Campos, J.F., U.P., Dos Santos, L.F.B., Macorini, A.M.M.F., De Melo, J.B. P., Balestieri, E.J., Paredes-Gamero, C.A.L., Cardoso, K.P., Souza, E.L. Santos. 2014. Antimicrobial, antioxidant and cytotoxic activities of propolis from Melipona orbignyi (Hymenoptera, Apidae). Food and Chem. Toxicol., 65: 374-380.

Campos, M.G.R., Bogdanov, S., De Almeida-Muradian, L.B., Szczesna, T., Mancebo, Y., Frigerio, C., Ferreira, F. 2008. Pollen composition and standardisation of analytical methods. J. Apicultural Res. Bee World, 47(2): 156-163.

Carpes, S.T., Begnini, R., De Alencar, S.M., Masson, M.L. 2007. Study of preparations of bee pollen extracts, Antioxidant and antibacterial activity. Ciênc. agrotec., Lavras., 31(6): 1818-1825.

Carpes, S.T., Mourão, G.B., De Alencar, S. M., Masson, M. L. 2009. Chemical composition and free radical scavenging activity of Apis mellifera bee pollen from Southern Brazil.

Braz. J. Food Technol., 12(3): 220229.

Chaillou, L., Nazareno, M.A. 2009. Bioactivity of propolis from Santiago del Estero, Argentina, related to their chemical composition. Food Sci. Technol., 42: 1422-1427.

Choudhari, M.K., Haghniaz, R., Rajwade, J.M., Paknikar, K.M. 2013. Anticancer Activity of Indian Stingless Bee Propolis: An In Vitro Study. Evid. Based Complement. Alternat. Med., eCAM, p. 10.

Coneac, G., Gafiţanu, E., Hădărugă, D.I., Hădărugă, N.G., Pînzaru, I.A., Bandur, G., Ursica, L., Păunescu, V., Gruia, A. 2008. Flavonoid Contents of Propolis from the West Side of Romania and Correlation with the Antioxidant Activity. Chem. Bull. "POLITEHNICA" Univ., (Timisoara). 53(67): 1-2.

Dehghani, H., Hashemi, M., Entezari, M., Mohsenifar, A. 2015. The Comparison of Anticancer Activity of Thymoquinone and Nanothymoquinone on Human Breast Adenocarcinoma. Iran J. Pharm. Res., 14(2): 539-546.

Fang, Y., Yang, S., Wu, G. 2002. Free radicals, antioxidants and nutrition. Nutrition. 18: 872-879. 
Garcia-Salas, P., Morales-Soto, A., SeguraCarretero, A., Fernández-Gutiérrez, A. 2010. Phenolic compoundextraction systems for fruit and vegetable samples. Molecules, 15: 8813-8826.

Goupy, P., Hugues, M., Boivin, P., Amiot, J. 1999. Antioxidant composition an activity of barley (Hordeum vulgare) and malt extracts and of isolated phenolic compounds. J. Sci. Food Agric., 79: 1625-1634.

Gregoris, E., Stevanato, R. 2010. Correlations between polyphenolic composition and antioxidant activity of Venetian propolis. Food Chem. Toxicol., 48: 76-82.

Gülçin, I. 2010. Antioxidant properties of resveratrol: a structure-activity insight. Innov. Food Sci. Emerg., 11: 210-218.

Gülçin, I., Mshvildadze, V., Gepdiremen, A., Elias, R. 2006. Antioxidant activity of a triterpenoid glycoside isolated from the berries of Hedera colchica: 3-O-( $\beta$-d-glucopyranosyl)hederagenin. Phytother. Res., 20: 130-134.

Haggag, E.E., Nafea, E., Wafa, A.Y. 2006. Chemical composition and antibacterial activity of honey bee glue (Propolis) collected from Egypt and Syria. J. Agric. Sci. Mansoura Univ., 31(9): 6039-6048.

Hajimehdipoor1, H., Shahrestani, R., Shekarchi, M. 2014. Investigating the synergistic antioxidant effects of some flavonoid and phenolic compounds. Res. J. Pharmacognosy (RJP), 1(3): 35-40.

Hegazi, A.G., Abd El Hady, F.K. 2002. Egyptian propolis: 3. Antioxidant, antimicrobial activities and chemical composition of propolis from reclaimed lands. Z. Naturforsch., 57: 395-402.
Hongzhuan, X., Zhen, L., Haiyue, Y., Qing, S., Kai, W., Qingtao, H., Yuanjun, W., Fuliang, H. 2014. Antitumor activity of chinese propolis in human breast cancer MCF-7 and MDA-MB231 Cells. Evidence-Based Complementary and Alternative Med., (1): 28-120.

Hossan, S., Rahman, S., Bashar, A.B.M.A., Jahan, R., Al-Nahain, A., Rahmatullah, M. 2014. Rosmarinic acid: a review of its anticancer action. World J. Pharm. Pharmaceutical Sci., 3(9): 57-70.

Houghton, P., Fang, R., Techatanawat, I., Steventon, G., Hylands, P.J., Lee, C.C. 2007. The sulphorhodamine (SRB) assay and other approaches to testing plant extracts and derived compounds for activities related to reputed anticancer activity. Methods, 42: 377-387.

Huang, S., Zhang, C., Wang, K., Li, G.Q., Hu, F. 2014. Recent Advances in the Chemical Composition of Propolis. Molecules, 19(12): 19610-19632.

Ibrahim, A.S., Khaled, H.M., Mikhail, N.N.H., Baraka, H., Kamel, H. 2014 .Cancer Incidence in Egypt: Results of the National Population-Based Cancer Registry Program. J. Cancer Epidemiol., (18): 437-971.

Jaitak, V., Sharma, K., Kalia, K., Kumar, N., Singh, H.P., Kaul, V.K., Singh, B. 2010. Antioxidant activity of Potentilla fulgens: An alpine plant of western Himalaya. J. Food Composition Anal., 23(2): 142-147.

Kaewmuangmoon, J., Nonthapa, P., Rattanawannee, A., Winayanuwattikun, P., Chanchao, C. 2012. Preliminary Screening for Various Bioactivities in Honey and Propolis Extracts from Thai Bees. Eur. J. Med. Pl., 2(2): 74-92. 
Kaneeda, J., Nishina, T. 1994. Safety of propolis. Acute toxicity. Honeybee Sci., 15: 29-33.

Khalil, M.L. 2006. Biological activity of bee propolis in health and disease. Asian Pacific J. Cancer Prevention. 7(1): 22-31.

Konishi, S., Sawaya, A., Custdio, A.R., Cunha, I., Shimizu, M. 2004. Influence of solubilising agents on antimicrobial activity of propolis extracts and of hydro alcoholic spray formula. Mensagem Doce (in Portuguese), 75: 22-25.

Kumazawa, S., Hamasaka, T., Nakayama, T. 2004. Antioxidant activity of propolis of various geographic origins. Food Chem., 84: 329-339.

Lotti, C., Fernandez, M.C., Piccinelli, A.L., Cuesta-Rubio, O., Hernandez, I.M., Rastrelli, L. 2010. Chemical Constituents of Red Mexican Propolis. J. Agric. Food Chem., 58: 2209-2213.

Mahmoud, A. M., El-Shemy, H.A. 2012. Cytotoxic Profiling of Some Compounds of Natural Origin against HepG2 Liver Cancer Cell Line in-vitro. J.Arid. Land Studies, 22(1): $191-194$.

Marcucci, M.C. 1995. Propolis: chemical composition, biological properties and therapeutic activity. Apidologie, 26: 83-99.

Mărghitaş, L.A., Stanciu, O.G., Dezmirean, D.S., Bobiş, O., Popescu, O., Bogdanov, S., Campos, M.G. 2009. In vitro antioxidant capacity of honeybee-collected pollen of selected floral origin harvested from Romania. Food Chem., 115: 878883.

Mattilla, P., Astola, J., Kumpulainen, J. 2000. Determination of flavonoids in plant material by HPLC with diodearray and electro-array detections. $J$.
Agric. Food Chem., 48: 5834-5841.

Meda, A., Lamien, C.E., Romito, M., Millogo, J., Nacoulma, O.G. 2005. Determination of the total phenolic, flavonoid and proline contents in Burkina Fasan honey, as well as their radical scavenging activity. Food Chem., 91: 571-577.

Mohammadzadeh, S., Shariatpanahi, M., Hamedi, M., Ahmadkhaniha, M., Samadi, R., Ostad, S.N. 2007. Chemical composition, oral toxicity and antimicrobial activity of Iranian propolis. Food Chem., 103(4): 10971103.

Morais, M., Moreira, L., Feas, X., Estevinho, L.M. 2011. Honeybeecollected pollen from five Portuguese Natural Parks: Palynological origin, phenolic content, antioxidant properties and antimicrobial activity. Food Chem. Toxicol., 49: 1096-1101.

Najafi, M.F., Vahedy, F., Seyyedin, M., Jomehzadeh, H.R., Bozary, K. 2007. Effect of the water extracts of propolis on stimulation and inhibition of different cells. Cytotechnol., 54: 49-56.

Natarajan, N., Thamaraiselvan, R., Lingaiah, H., Srinivasan, P., Periyasamy, B.M. 2011. Effect of flavonone hesperidin on the apoptosis of human mammary carcinoma cell line MCF-7. Biomed. Preventive Nutrition, 1(3): 207-215.

Ohta, S., Fujimaki, T., Uy, M..M, Yanai, M., Yukiyoshi, A., Hirata, T. 2007. Antioxidant hydroxycinnamic acid derivatives isolated from Brazilian bee pollen. Natural Product Res., 21(8): 726-32.

Osuntoki, A., Korie, I. 2010. Antioxidant Activity of Whey from Fermented Milk. Food Technol. Biotechnol., 48(4): 505-511. 
Pereira, A.D., Faloni de Andrade, S., Swerts, M.S.O., Maistro, E.L. 2008. First in vivo evaluation of the mutagenic effect of Brazilian green propolis by comet assay and micronucleus test. Food Chem. Toxicol., 46: 2580-2584.

Rice-Evans, C.A., Miller, N.J., Paganga, G. 1996. Structure-antioxidant activity relationships of flavonoids and phenolic acids. Free Radical Bio. Med., 20: 933-956.

Seelinger, G., Merfort, I., Wölfle, U., Schempp, C.M. 2008. Anticarcinogenic Effects of the Flavonoid Luteolin. Molecules, 13: 2628-2651.

Senedese, J.M., Rodrigues, A.R., Furtado, M.A., Faustino, V.D., Berretta, A.A., Marchetti, J.M., Tavares, D.C. 2011. Assessment of the mutagenic activity of extracts of brazilian propolis in topical pharmaceutical formulations on mammalian cells in vitro and in vivo. Evid. Based Complement. Alternat. Med., 315-701.

Slavova, A.M., Trifonova, A., Peychevb, L., Dimitrovab, S., Peychevab, S., Gotchevaa, V., Angelova, A. 2013. Biologically Active Compounds with Antitumor Activity in Propolis Extracts from Different Geographic Regions. Biotechnol. Biotechnol. Eq., 27(4): 4010-4013.

Sobolova, L., Skottova, N., Vecera, R., Urbanek, K. 2006. Effect of silymarin and its polyphenolic fraction on cholesterol absorption in rats. Pharma. Res., 53: 104-112.

Son, H.L., Anh, N.P. 2013. Phytochemical composition, in vitro antioxidant and anticancer activities of quercetin from methanol extract of Asparagus cochinchinensis (LOUR.) Merr. Tuber. J. Med. Plants Res., Vol.7(46): 3360-3366.
Sun, C., Wu, Z., Wang, Z., Zhang, H. 2015. Effect of Ethanol/Water Solvents on Phenolic Profiles and Antioxidant Properties of Beijing Propolis Extracts. Evid. Based Complement. Alternat. Med., (9): 595393.

Tai, A., Sawano, T., Yazama, F. 2011. Antioxidant Properties of Ethyl Vanillin in Vitro and in Vivo. Biosci. Biotechnol. Biochem., 75(12): 23462350.

Tang, B., Zhang, L., Geng, Y. 2005. Determination of the antioxidant capacity of different food natural products with a new developed flow injection spectrofluorimetry detecting hydroxyl radicals. Talanta, [S.l.], 65(3): 769-775.

Valente, M.J., Baltazar, A.F., Henrique, R., Estevinho, L., Carvalho, M. 2011. Biological activities of Portuguese propolis: Protection against free radical-induced erythrocyte damage and inhibition of human renal cancer cell growth in vitro. Food Chem. Toxicol., 49: 86-92.

Vatansever, H.S., Sorkun, K., Gurhan, S.I.D., Kurt, F.O., Turkoz, E., Gencay, O., Salih, B. 2010. Propolis from Turkey induces apoptosis through activating caspases in human breast carcinoma cell lines. Acta. Histochemica., 112(6): 546-556.

Vongsak, B., Kongkiatpaiboon, S., Jaisamut, S., Machana, S., Pattarapanich, C. 2015. In vitro alpha glucosidase inhibition and free-radical scavenging activity of propolis from Thai stingless bees in mangosteen orchard, Revista Brasileira de Farmacognosia. 25(5): 445-450.

Wang, B., Diao, Q., Zhang, Z., Liu, Y., Gao, Q., Zhou, Y., Li, S. 2013. Antitumor activity of bee pollen polysaccharides from Rosa rugosa. Mol. Med. Reports, 7(5): 1555-1558. 
Wang, H., Gao, X.D., Zhou, G.C., Cai, L., Yao, W.B. 2008. In vitro and in vivo antioxidant activity of aqueous extract from Choerospondias axillaris fruit. Food Chem., 106: 888-895.

Wang, T., Zhang, J.C., Chen, Y., Huang, F., F., Yang, M.S., Xiao, P.G. 2007. Comparison of antioxidative and antitumor activities of six flavonoids from Epimedium koreanum [Article inChinese]. Zhongguo Zhong Yao Za Zhi. 32: 715-718.

Watanabe, M.A.E., Amarante, M.K., Conti, B.J., Sforcin, J.M. 2011. Cytotoxic constituents of propolis inducing anticancer effects: a review. $J$. Pharm. Pharmacol., 63: 1378-1386.

World Health Organization, 2013. Cancer mortality and morbidity. URL $<$ http://www.who.int/gho/ncd/mortal ity_morbidity/cancer_text/en/>.

Zliszka, E., Czuba, Z.P., Bronikowska, J., Mertas, A., Paradysz, A., Krol, W. 2011. Ethanolic extract of propolis augments TRAIL-induced apoptotic death in prostate cancer cells. Evid. Based Complement. Alternat. Med., (11): 535172 .

\section{How to cite this article:}

Hala M. Abu Shady, Wafaa F. mohamed, ElSayed F. Sayed-Ahmed and Sara A. Amer. 2016. A Comparative Study on Propolis and Pollen Extracts: Chemical Profile Analysis, Antioxidant and Anticancer Activity. Int.J.Curr.Microbiol.App.Sci. 5(3): 397-414. doi: http://dx.doi.org/10.20546/ijcmas.2016.503.047 